Summer 9-2010

\title{
The Sustainability Liability: Potential Negative Effects of Ethicality on Product Preference
}

\author{
Michael G. Luchs \\ College of William and Mary, michael.luchs@mason.wm.edu \\ Rebecca W. Naylor \\ The Ohio State University, naylor_53@fisher.osu.edu \\ Julie R. Irwin \\ University of Texas at Austin, julie.irwin@mccombs.utexas.edu \\ Rajagopal Raghunathan \\ University of Texas at Austin, raj.raghunathan@mccombs.utexas.edu
}

Follow this and additional works at: https://scholarworks.wm.edu/businesspubs

Part of the Other Business Commons, and the Sales and Merchandising Commons

\section{Recommended Citation}

Luchs, Michael G., Rebecca Walker Naylor, Julie R. Irwin and Rajagopal Raghunathan (2010), "The Sustainability Liability: Potential Negative Effects of Ethicality on Product Preference", Journal of Marketing, 74(5): 18-31 


\section{The Sustainability Liability: Potential Negative Effects of Ethicality on Product Preference}

Manufacturers are increasingly producing and promoting sustainable products (i.e., products that have a positive social and/or environmental impact). However, relatively little is known about how product sustainability affects consumers' preferences. The authors propose that sustainability may not always be an asset, even if most consumers care about social and environmental issues. The degree to which sustainability enhances preference depends on the type of benefit consumers most value for the product category in question. In this research, the authors demonstrate that consumers associate higher product ethicality with gentleness-related attributes and lower product ethicality with strength-related attributes. As a consequence of these associations, the positive effect of product sustainability on consumer preferences is reduced when strength-related attributes are valued, sometimes even resulting in preferences for less sustainable product alternatives (i.e., the "sustainability liability"). Conversely, when gentleness-related attributes are valued, sustainability enhances preference. In addition, the authors show that the potential negative impact of sustainability on product preferences can be attenuated using explicit cues about product strength.

Keywords: sustainability, ethical products, green marketing, implicit associations, corporate social responsibility

$\mathbf{P}$ roducts that espouse positive social and environmental ethical principles have received considerable attention in recent years. Stories about "ethical consumers" and terms such as "green" and "sustainable" appear regularly in such popular press outlets as BusinessWeek (Beaven 2009), Time Magazine (Betts 2009), and the Wall Street Journal (Johnson 2009). Companies are responding to this heightened attention with new brand and product introductions (e.g., Clorox's new line of household cleaners; see Story 2008), and retailers (e.g., Wal-Mart, Whole Foods) are responding with comprehensive sustainability initiatives (Gunther 2006; Whole Foods Market 2010).

Despite the widespread attention sustainability is receiving, sales of sustainable products (i.e., products with positive social and/or environmental attributes) still repre-

Michael G. Luchs is Assistant Professor of Marketing, Mason School of Business, College of William and Mary (e-mail: michael.luchs@mason. wm.edu). Rebecca Walker Naylor is Assistant Professor of Marketing, Fisher College of Business, Ohio State University (e-mail: naylor_53@ fisher.osu.edu). Julie R. Irwin is Professor of Marketing (e-mail: julie.irwin@mccombs.utexas.edu), and Rajagopal Raghunathan is Associate Professor of Marketing (e-mail: raj.raghunathan@mccombs.utexas. edu), McCombs School of Business, University of Texas at Austin. The authors thank Sunaina Chugani, Joseph Goodman, Leonardo Nicolao, David Norton, Nita Umashankar, and Morgan Ward for their assistance in data collection. This project was funded by a Transformative Consumer Research grant from the Association for Consumer Research. A previous version of this article received a best paper award at the inaugural Transformative Consumer Research conference held at the Tuck School at Dartmouth (2007). sent "only a small fraction of overall demand" (United Nations Environment Programme 2005, p. 3), and there appears to be a significant gap between consumers' explicit attitudes toward sustainable products and their consumption behavior. For example, one study suggests that though $40 \%$ of consumers report that they are willing to buy "green products," only 4\% actually do so (United Nations Environment Programme 2005, p. 15).

There are many potential reasons for the relatively low market share of sustainable products. These products often are priced higher than their mainstream counterparts (Consumer Reports 2007) and often have relatively limited distribution. However, these factors alone cannot fully explain differences in the success of sustainable products across product categories. Although the market share of sustainable products has been relatively weak in many product categories, such as household cleaning products, it has been relatively strong in other categories, such as personal care products (Porges 2007). This qualified success of sustainable products hints at a variable that is differentially affecting the influence of sustainability on preference.

We propose that though sustainability may be valued in and of itself, it also affects perceptions of a product's other attributes. As such, the extent to which increasing sustainability enhances the product's appeal depends on the type of benefit consumers value in a given product category. Furthermore, we propose that there are some situations in which the benefit of sustainability is offset to such an extent that consumers prefer less sustainable products even though they may care about ethical issues. We also explore a question that 
naturally follows from this proposition: What can marketers do to overcome the sustainability liability (when it exists) and, thus, to increase the appeal of sustainable products?

\section{Theory and Hypotheses}

Ethical attributes are attributes that reflect moral principles (Baron and Spranca 1997; Ehrich and Irwin 2005; Irwin and Baron 2001; Irwin and Naylor 2009). These attributes are related to a variety of social issues (e.g., fair labor practices, humane treatment of animals) and environmental issues (e.g., recycling, avoiding pollution). Although prior literature has often referred to "ethical attributes" and "ethical products," the term "sustainable" is commonly used in industry practice. Thus, although we draw from a rich literature in ethics to develop our hypotheses, we also use the term "sustainable" to refer to products with positive ethical attributes.

There is evidence that consumers view sustainable products positively. For example, the findings from a recent survey revealed that most U.S. consumers indicate that they would choose a product from an environmentally friendly company if it cost the same as other available alternatives (BBMG 2007). Echoing these findings, in another recent survey (Trudel and Cotte 2008), consumers reported being willing to pay a premium for ethically produced goods. Thus, ethicality seems to be a benefit for many consumers.

Conversely, there is evidence that increasing product ethicality may not always increase preference. Although people value ethicality, it may not necessarily follow that they prefer sustainable products. For example, researchers have found that improving corporate social responsibility (CSR), which refers to the ways a firm addresses societal and stakeholder obligations (Luo and Bhattacharya 2006), does not always translate into benefits for the company (Luo and Bhattacharya 2006; Sen and Bhattacharya 2001). Although some research (Brown and Dacin 1997) has shown that a favorable CSR record is positively related to overall product evaluation, more recent findings have suggested that a positive CSR record can have a negative effect. Specifically, when products are high quality, a positive CSR record can lower purchase intentions (Sen and Bhattacharya 2001), and when firms are perceived as less innovative, CSR can decrease customer satisfaction and financial returns (Luo and Bhattacharya 2006).

This prior literature on CSR has primarily explored how a company's overall CSR record (e.g., its record with regard to diversity) interacts with other firm-level attributes (Luo and Bhattacharya 2006) and consumer-level individual difference variables (Sen and Bhattacharya 2001) to influence evaluations of the company's product lines. The current research aim is broadly related to this prior research because we also consider the ways ethical superiority might or might not benefit a company.

Specifically, we propose that in addition to the benefit of being perceived as a sustainable product, the presence of an ethical attribute can influence consumer perceptions of other valued attributes, which in turn can affect product preference. As we review subsequently, one set of extant consumer behavior theories predicts that the presence of a positive ethical attribute could lead to positive perceptions of a product's other attributes, and another set of theories predicts that these perceptions could be negative.

\section{Prior Research Predicting a Positive or Negative Effect of Ethicality on Product Preference}

When a product includes a positive attribute, this positivity often extends to other product attributes. Research on halo effects (e.g., Asch 1946; Nisbett and Wilson 1977; Thorndike 1920), the affect heuristic (Finucane et al. 2000), and schema-consistent judgments (e.g., Fiske and Pavelchak 1986) suggests that if a product is judged to be superior on one observable attribute, it will also be perceived favorably along other attribute dimensions. This prior research implies that if ethical superiority is valued, other attributes of sustainable products will be viewed more positively as well.

However, other research streams suggest that the presence of a desirable attribute can have a negative effect on the perception of other product attributes. Consumers are aware that manufacturers operate under budgetary, product development, and manufacturing constraints. Given the behavioral implications of efficient markets (Chernev and Carpenter 2001), consumers may infer that products that are superior on one attribute will be relatively inferior on other attributes. This prior research implies that the presence of a positive ethical attribute would result in the expectation of decreased performance on other attributes.

Halo effects and beliefs about the trade-offs required in efficient markets would imply a unidirectional effect of ethicality on product preference (i.e., sustainable products would be preferred if halo effects prevailed and not preferred if beliefs about trade-offs in efficient markets prevailed). We propose a new factor that also influences consumers' preferences for sustainable products but results in a more complex relationship between sustainability and preference-namely, the type of benefit sought from the product. We argue that ethicality is positively associated with some types of benefits and negatively associated with other types of benefits.

\section{The Positive Association Between Ethicality and Gentleness (Versus Strength)}

In a 2001 nationwide survey of 1037 U.S. households, consumers indicated that they associate a socially conscious company with attributes such as "safe," "friendly," and "protective" (Gildea 2001). More recently, we asked 23 MBA survey respondents to list attributes on which ethical products might be assumed to have better performance than less ethical products. Almost half the respondents (11/23) listed attributes consistent with the idea that products with positive ethical attributes might be safer, healthier, and gentler than other products (e.g., [ethical products are] "safer for you and your family," "better for you," and "more gentle on a person's body"). This exploratory research suggests that consumers associate ethicality with gentleness-related attributes.

These findings are consistent with research in organizational behavior and human relations (e.g., Kanov et al. 2004; Luthans and Youssef 2007; O’Donohoe and Turley 
2006; Sisodia, Sheth, and Wolfe 2007), which has attempted to map the network of traits associated with ethical and morally upright behavior. This work shows that a defining characteristic of ethical agents, such as ethical leaders and managers, is compassion and caring (Luthans and Youssef 2007; Sisodia, Sheth, and Wolfe 2007). Because compassion involves being able not only to notice the pain of another but also even to feel this pain (Kanov et al. 2004), ethicality carries with it an association of being "gentle" and perhaps even "weak"; conversely, a lack of ethicality is associated with being especially concerned with "getting the job done," even if it comes at a cost to others.

Indeed, a prevalence of sociocultural messages suggests a conflict between ethicality and strength. Sociocultural messages can exert a powerful influence on behavior (Raghunathan, Naylor, and Hoyer 2006) through lay beliefs (Morris, Menon, and Ames 2001), linking concepts that, over time, become automatically commingled in the minds of members of the culture (Gini 2006). ${ }^{1}$ Common expressions such as "nice guys finish last" and "to make an omelet, you have to break some eggs" imply that amorality is positively related to strength and success. In his book Why It's Hard to Be Good, Al Gini (2006) expands on this notion and notes that the "rugged individualist" is one of the most enduring icons in North American culture-the amoral pirate, cowboy, gangster, or other type of rogue who ignores ethical rules and who is macho and tough.

We argue that the positive association between ethicality and gentleness and the negative association between ethicality and strength is transferred from the context of social judgments to the context of product judgments. This transference is especially relevant in the case of sustainability because consumers may not have perfect information about how strong or gentle a sustainable product is or how sustainability might affect the product's performance, and thus they infer these effects using prior experiences and knowledge (for a discussion of consumer inference making, see Dick, Chakravarti, and Biehal 1990; Sujan and Dekleva 1987). Lay theories about the relationship between missing and available product attribute information are a common way for consumers to form inferences when making product judgments (Broniarczyk and Alba 1994; Raghunathan, Naylor, and Hoyer 2006). In the current research, because of consumers' associations with the relationship between ethicality and strength/gentleness, they assume that products can be either ethical or strong, but not both.

Documenting evidence in support of the proposed relationship between ethicality and gentleness/strength not only is theoretically worthwhile but also has important practical implications. Gentleness-related and strength-related attributes are valued in many product categories. ${ }^{2}$ For example,

1One source of lay beliefs can be lay inferencing (Kelly and Thibaut 1969); consumers may learn to associate ethicality with lack of strength through direct experience with both people and products that are ethical but not strong, and vice versa.

2Although we chose the terms "gentleness" and "strength," it is best to think of these terms as referring to a cluster of attributes that provide consumers related benefits, such as safety and health and power and durability, respectively. consumers are especially likely to value gentleness in categories such as baby shampoo, facial soaps, and body lotion, and they are especially likely to value strength in categories such as laundry detergents, hand sanitizers, and car tires. We propose that associations with ethicality will differentially drive preference for sustainable products, depending on the primary benefit sought in the product category. Thus:

$\mathrm{H}_{1}$ : Consumers associate higher (versus lower) ethicality with gentleness-related attributes and lower (versus higher) ethicality with strength-related attributes.

$\mathrm{H}_{2}$ : Sustainability enhances product preferences to a greater extent when gentleness-related attributes are valued than when strength-related attributes are valued. When strengthrelated attributes are valued, the benefit of sustainability is attenuated, in some cases even resulting in greater preference for less sustainable products.

\section{Overcoming the Sustainability Liability}

In product categories in which gentleness-related attributes are valued, we argue that ethicality is an asset and, thus, that sustainability enhances preference for the product. In product categories in which strength-related attributes are valued, sustainability could be a liability, as we propose in $\mathrm{H}_{2}$. Therefore, marketers might logically ask how they can overcome potential negative associations between ethicality and product strength. Our prior discussion of the association between ethicality and lack of strength suggests a possible solution. Managers may be able to overcome the sustainability liability by providing explicit information about product strength, mitigating consumers' reliance on a default inference about a negative relationship between sustainability and strength. Therefore, we propose the following hypothesis:

$\mathrm{H}_{3}$ : Sustainability is less of a liability when sustainable products are explicitly portrayed as being strong than when no such strength information is provided.

\section{Eliciting Implicit Preference}

Before introducing the studies, we note that consumers may be motivated to explicitly express a consistently positive relationship among sustainability, product strength, and product preference in all product categories. They may be motivated to do so either to perceive or to present themselves in a more positive light (i.e., to respond in a socially desirable manner; Fisher 1993; Paulhus 1984). People seem to be particularly motivated to present themselves as more conscientious and moral than others; thus, the motivation for self-presentation is particularly salient in the context of judging ethicality (Epley et al. 2004; Kruger and Gilovich 2004). Historically, researchers interested in eliciting beliefs that consumers may not be willing to articulate explicitly have used indirect techniques of inquiry (Alpert 1971; Blatt 1975; Haire 1950; Hussey and Duncombe 1999). We use two such techniques: the implicit association test (IAT) (Greenwald, McGhee, and Schwartz 1998) and a projective technique that involves asking participants to identify which product the "average person" would prefer (for a discussion of similar indirect questioning methods, see Fisher 1993). Projective techniques of this nature do not 
necessarily give researchers better insight into participants' true attitudes and preferences in every situation, but they are particularly useful in contexts in which respondents may be reluctant to fully express themselves because of concerns about expressing socially undesirable opinions.

\section{Study 1: Implicit Association Test}

In Study 1, we conducted an IAT, an established tool for demonstrating implicit associations between concepts (Greenwald, McGhee, and Schwarz 1998), to demonstrate that consumers associate higher ethicality with gentlenessrelated attributes and lower ethicality with strength-related attributes $\left(\mathrm{H}_{1}\right)$.

\section{Stimuli}

We draw stimuli for the IAT from the following four categories: (1) words and phrases describing an ethical company/ the practices of an ethical company ("fair labor practices," "cares about the environment," "sustainable development," “"green' company," "socially responsible”); (2) words and phrases describing a less ethical, self-interested (and potentially exploitative) company ("profit at all costs," "exploitative," "selfish," "self-centered," "short-term goals"); (3) words and phrases associated with gentle products (e.g., "safe product," "mild product," "healthy product," "good for children," "soft product"); and (4) words and phrases associated with strong products (e.g., "powerful product," "tough product," "gets the job done," "harsh product," "effective product").

\section{Participants and Procedure}

Forty-two undergraduate students participated in this study for course credit. The task consisted of categorizing stimuli from the four categories as the words/phrases were shown on the middle of their computer screens (category labels were displayed at the top of the screen). In line with established protocol (Greenwald, McGhee, and Schwarz 1998), participants completed seven blocks of trials, five of which were practice blocks. Stimuli from all four categories (selfinterested company words/phrases, ethical company words/ phrases, gentle product words/phrases, and strong product words/phrases) were presented for classification in blocks 3, 4, 6, and 7 for a total of 200 trials per participant across these four blocks (for details, see Table 1). There were two critical blocks: block 4, in which the category labels were "Self-Interested Company or Gentle Product" versus "Ethical Company or Strong Product," and block 7, in which the category labels were "Ethical Company or Gentle Product" and "Self-Interested Company or Strong Product." Note that block 4 was the hypothesis-inconsistent condition in which the pairings between ethicality and type of benefit valued were the opposite of our predictions, and block 7 was the hypothesis-consistent condition. An implicit association between higher ethicality and gentleness (and between lower ethicality and strength) would be reflected in faster response latencies when the classification task was consistent (versus inconsistent) with $\mathrm{H}_{1}$.

\section{Data Preparation}

We followed the revised IAT scoring algorithm (Greenwald, Nosek, and Banaji 2003), which resulted in a final sample of 39 participants who satisfied all criteria. Next, we computed two difference scores reflecting the difference in response latencies between the blocks that were consistent with the hypothesis and those that were inconsistent: (hypothesis-consistent) - (hypothesis-inconsistent). The first difference score uses critical test blocks 7 and 4, and the second uses practice blocks 6 and 3 (see Table 1). We then divided each difference score by the pooled standard deviation of response latencies for the associated blocks and averaged the quotients. The resultant measure is termed the "IAT D effect" (Greenwald, Nosek, and Banaji 2003).

\section{Results and Discussion}

Response times were significantly faster in the hypothesisconsistent than in the hypothesis-inconsistent blocks $(\mathrm{F}(1$, $38)=59.60, p<.0001, \mathrm{D}=1.00)$. Mean response time when participants classified stimuli into the hypothesis-consistent categories (i.e., pairing words describing less ethical, selfinterested companies with words about product strength) was 1050.62 milliseconds in critical test block 7, compared with 1474.91 milliseconds in the hypothesis-inconsistent (i.e., pairing words describing ethical companies with words about product strength) critical test block 4. Thus, in support of $\mathrm{H}_{1}$, participants implicitly associate higher ethicality with gentleness-related product attributes and lower ethicality with strength-related product attributes.

TABLE 1

Study 1: Sequence of Trial Blocks in IAT

\begin{tabular}{|c|c|c|c|c|}
\hline Block & $\begin{array}{c}\text { Number of } \\
\text { Trials }\end{array}$ & Function & $\begin{array}{l}\text { Items Assigned to } \\
\text { Left-Key Response }\end{array}$ & $\begin{array}{l}\text { Items Assigned to } \\
\text { Right-Key Response }\end{array}$ \\
\hline 1 & 20 & Practice & Self-interested company & Ethical company \\
\hline 2 & 20 & Practice & Gentle product & Strong product \\
\hline 3 & 20 & $\begin{array}{l}\text { Practice for critical } \\
\text { test block }\end{array}$ & $\begin{array}{l}\text { Self-interested company } \\
\text { or gentle product }\end{array}$ & $\begin{array}{l}\text { Ethical company or } \\
\text { strong product }\end{array}$ \\
\hline 4 & 40 & $\begin{array}{l}\text { Hypothesis-inconsistent } \\
\text { critical test block }\end{array}$ & $\begin{array}{c}\text { Self-interested company or } \\
\text { gentle product }\end{array}$ & $\begin{array}{c}\text { Ethical company or } \\
\text { strong product }\end{array}$ \\
\hline 5 & 40 & Practice & Ethical company & Self-interested company \\
\hline 6 & 20 & $\begin{array}{c}\text { Practice for critical } \\
\text { test block }\end{array}$ & $\begin{array}{l}\text { Ethical company or } \\
\text { gentle product }\end{array}$ & $\begin{array}{l}\text { Self-interested company } \\
\text { or strong product }\end{array}$ \\
\hline 7 & 40 & $\begin{array}{l}\text { Hypothesis-consistent } \\
\text { critical test block }\end{array}$ & $\begin{array}{l}\text { Ethical company or } \\
\text { gentle productor }\end{array}$ & $\begin{array}{l}\text { Self-interested company } \\
\text { or strong product }\end{array}$ \\
\hline
\end{tabular}




\section{Addressing Potential Valence Confound}

If gentleness is less positively valenced than strength in a product context, a valence match between ethicality and strength and between self-interest and gentleness could induce the results. ${ }^{3}$ To test this possibility, we asked 159 participants to rate the valence of the words/phrases used in the IAT (i.e., "whether it's a good thing or a bad thing if a company/product and/or its practices are described this way"). The average valences for the words/phrases belonging to the "strong" $(M=6.66)$ and "gentle" $(M=6.65)$ categories were not significantly different $(\mathrm{F}(1,158)=.01, p=$ $.94)$, but as we expected, the words/phrases describing a "self-interested" company were rated as significantly more negative $(\mathrm{M}=3.35)$ than the words/phrases in the "ethical" company category $(\mathrm{M}=7.62 ; \mathrm{F}(1,158)=1172.70, p<$ .0001). Thus, the results of Study 1 document an association between gentleness and ethicality and between strength and self-interest, and not a valence match. Nevertheless, these results are merely suggestive with respect to product preferences. Study 2 tests actual preference using two related product categories to explore whether ethicality is more of an asset when gentleness-related than when strength-related attributes are valued, as we predict in $\mathrm{H}_{2}$.

\section{Study 2: Product Preference When Gentleness-Related Versus Strength-Related Attributes Are Valued}

The primary objective of Study 2 was to demonstrate that the effect of sustainability on product preferences is moderated by the type of benefit sought in the product category (gentleness versus strength). To accomplish this objective, we used two closely related product categories: baby shampoo and car shampoo. Presumably, both gentleness and strength are important whether washing a car or a child's hair. However, we propose that strength-related attributes are more important for car shampoo and that gentleness-related attributes are more important for baby shampoo. To affirm these expectations, we conducted a pretest.

\section{Pretest}

Seventy-six undergraduate students were randomly assigned to one of the two categories and were asked to "rate how important each of the following dimensions/characteristics is to you when you buy car shampoo [baby shampoo]." We used the eight attributes most relevant to these product categories from the IAT (Study 1), as well as the product attribute category labels from the IAT, namely, "strong" and "gentle." A factor analysis of the attribute importance measures revealed two factors (both with eigenvalues above 2.0), Strong and Gentle. We calculated the Strong factor using the average of the measures for the importance of "strong," "powerful," "tough," "effective," and "gets the job done" (Cronbach's $\alpha=.82$ ). We calculated the Gentle factor using the average of the measures for the importance of "gentle," "safe," "healthy," "a 'good for children' product," and "mild"

\footnotetext{
${ }^{3}$ We thank an anonymous reviewer for this suggestion.
}

(Cronbach's $\alpha=.80$ ). We analyzed relative importance ratings for baby versus car shampoo and found that, as expected, Gentle was more important than Strong for baby shampoo $\left(\mathrm{M}_{\text {difference score for Gentle }- \text { Strong }}=2.40\right)$ and Strong was more important than Gentle for car shampoo $\left(\mathrm{M}_{\text {difference score for }}\right.$ Gentle - Strong $=-1.26 ; \mathrm{F}(1,74)=127.79, p<.0001)$.

\section{Stimuli and Procedure}

One hundred forty-eight undergraduate students participated in the main study in exchange for extra course credit. Participants indicated their relative preference between two brands that varied in their level of sustainability. We manipulated sustainability using a statement from a hypothetical independent agency, the "Ethical Product Council (EPC)." The EPC "rates similar products based along a variety of proenvironmental and prosocial factors such as sensitivity about pollution and resource usage as well as fair treatment of staff, suppliers, and communities." As Figure 1 shows, although the description of the size, uses, and availability of the shampoos remained constant, we told participants that the two shampoos received different EPC ratings ( 5 = "average" versus $10=$ "superb").

\section{FIGURE 1 \\ Study 2: Manipulation of Sustainability for Baby and Car Shampoos}

\begin{tabular}{|c|c|c|}
\hline & Baby Sh & ampoo \\
\hline & Brand A & Brand B \\
\hline Size & 24 oz. bottle & 24 oz. bottle \\
\hline Uses & $\begin{array}{l}\text { Shampooing hair } \\
\text { of children under } \\
3 \text { years old }\end{array}$ & $\begin{array}{l}\text { Shampooing hair } \\
\text { of children under } \\
3 \text { years old }\end{array}$ \\
\hline Availability & $\begin{array}{l}\text { Mass merchandis- } \\
\text { ers, specialty } \\
\text { baby stores, some } \\
\text { grocery stores }\end{array}$ & $\begin{array}{l}\text { Mass merchandis- } \\
\text { ers, specialty } \\
\text { baby stores, some } \\
\text { grocery stores }\end{array}$ \\
\hline $\begin{array}{l}\text { EPC rating } \\
\text { (see below) }\end{array}$ & 10 (superb) & 5 (average) \\
\hline $\begin{array}{l}\text { The Ethical Prod } \\
\text { along a variety of } \\
\text { sensitivity about } p \\
\text { ment of staff, sup }\end{array}$ & $\begin{array}{l}\text { ouncil (EPC) rates s } \\
\text { nvironmental and pro } \\
\text { on and resource usag } \\
\text { and communities. }\end{array}$ & $\begin{array}{l}\text { nilar products based } \\
\text { ocial factors such as } \\
\text { as well as fair treat- }\end{array}$ \\
\hline & Car Sh & lampoo \\
\hline & Brand X & Brand Y \\
\hline Size & 24 oz. bottle & 24 oz. bottle \\
\hline Uses & $\begin{array}{c}\text { Washing cars and } \\
\text { trucks }\end{array}$ & $\begin{array}{c}\text { Washing cars and } \\
\text { trucks }\end{array}$ \\
\hline Availability & $\begin{array}{l}\text { Mass merchandis- } \\
\text { ers, specialty auto } \\
\text { stores, some } \\
\text { grocery stores }\end{array}$ & $\begin{array}{l}\text { Mass merchandis- } \\
\text { ers, specialty auto } \\
\text { stores, some } \\
\text { grocery stores }\end{array}$ \\
\hline $\begin{array}{l}\text { EPC rating } \\
\text { (see below) }\end{array}$ & 10 (superb) & 5 (average) \\
\hline
\end{tabular}

The Ethical Product Council (EPC) rates similar products based along a variety of proenvironmental and prosocial factors such as sensitivity about pollution and resource usage as well as fair treatment of staff, suppliers, and communities. 
Participants reported their relative preference for the sustainable and the less sustainable brands of car shampoo (intended for "washing cars and trucks") and their relative preference for the sustainable and the less sustainable brands of baby shampoo (intended for shampooing the "hair of children under three years old"). We counterbalanced the order of the preference task for the two types of shampoo. We also counterbalanced the brand names to be either Brand A and B for the product category that appeared first or Brand X and Y for the product category that appeared second. Brand A and X were always on the left-hand side of the computer screen, but we also counterbalanced which of these two brands was the sustainable brand. Participants reported their preference for the two brands on a nine-point rating scale anchored by the two brands (e.g., "Which of these two shampoos would you choose?" with "definitely Brand A" and "definitely Brand B" as the anchors).

Recall that it is likely that participants are motivated to present themselves in a positive light when ethics are involved (Epley et al. 2004; Kruger and Gilovich 2004). To address this possibility, half the participants indicated their own preferences (the Self condition), and the other half provided ratings on behalf of the "average American consumer" (the Other condition). We expected the responses of participants in the Other condition to be more reflective of their true preferences. Thus, Study 2 had one within-subjects factor-Shampoo Type (Baby versus Car Shampoo)-and three between-subjects factors-Point of View (Self versus Other), Order of Presentation of Product Categories (Baby Shampoo First versus Car Shampoo First), and Order of Presentation of the Sustainable Brand (Left versus Right).

After the preference task, participants indicated (as a manipulation check for each type of shampoo) which brand was manufactured by a company with higher ethical standards. Finally, participants in the Other condition completed another manipulation check to ensure that they had indeed provided ratings based on the average American consumer's beliefs (and not their own). ${ }^{4}$

\section{Results}

We converted participants' ratings of the ethical standards of the manufacturing company and their brand preference ratings so that the sustainable brand always anchored the high end of the scale (corresponding to a rating of nine).

Data preparation and manipulation check. We removed 5 participants from the Other condition from the sample because they failed the manipulation check, which asked them if their responses were based on what the average American consumer believed. 5 Therefore, we had a final

${ }^{4}$ In this and subsequent studies, participants in the Self condition were not subject to a similar manipulation check because we assumed that people would naturally indicate preferences on their own behalf when not instructed otherwise.

${ }^{5}$ The results when we retained participants who failed this manipulation check were similar to those when we dropped these participants. A significant Shampoo Type main effect $(\mathrm{F}(1,140)=$ $9.35, p<.01)$, a significant Point of View main effect $(\mathrm{F}(1,140)=$ $12.30, p<.001)$, and a marginally significant Shampoo Type $\times$ Point of View interaction $(\mathrm{F}(1,140)=2.96, p=.09)$ also emerged in the full data set. usable sample of 143 participants. The manipulation of sustainability was successful in that participants correctly identified which baby shampoo brand and which car shampoo brand was produced using higher ethical standards $\left(\mathrm{M}_{\text {baby }}\right.$ shampoo $=8.59$ and $\mathrm{M}_{\text {car shampoo }}=8.52$, both means significantly different from the scale midpoint of five; $\mathrm{F}(1,142)=$ $2965.21, p<.0001$, and $\mathrm{F}(1,142)=1573.14, p<.0001$, respectively).

Preference results. A repeated measures analysis tested the relative preference for the sustainable brand of baby versus car shampoo. Point of View (Self versus Other), Order of Presentation of Product Categories (Baby Shampoo First versus Car Shampoo First), and Order of Presentation of the Sustainable Brand (Left versus Right) were between-subjects factors in this analysis. There was one main effect of order. Participants had greater relative preference for the sustainable brand across both product categories when they were asked about baby shampoo first $(\mathrm{F}(1,135)=6.45, p<.05) .{ }^{6}$ There were no other main or interactive effects of either order factor.

Consistent with $\mathrm{H}_{2}$, preference for the sustainable brand of baby shampoo $(\mathrm{M}=7.48)$ was significantly greater than preference for the sustainable brand of car shampoo $(\mathrm{M}=$ $6.83) ; \mathrm{F}(1,135)=11.91, p<.001)$. We expected this difference because the pretest results showed that gentleness is more valued in the category of baby (versus car) shampoo. We also found a significant main effect of Point of View on preferences $(\mathrm{F}(1,135)=14.59, p<.001)$, presumably because participants in the Self condition were motivated to express preference for the sustainable brand of shampoo even if they did not actually prefer it. As Figure 2 shows, there was a greater preference for the sustainable brands in the Self condition than in the Other condition.

The power of the projective technique becomes even more apparent in the significant interaction between Point of View and Shampoo Type $(\mathrm{F}(1,135)=4.50, p<.05)$ (see Figure 2). Note that in the Self condition, preference was overwhelmingly in favor of the sustainable alternative; spotlight analyses (Irwin and McClelland 2001) reveal that there was no difference in preference for the sustainable baby shampoo versus sustainable car shampoo in the Self condition $\left(\mathrm{M}_{\text {baby shampoo }}=7.73\right.$ and $\mathrm{M}_{\text {car shampoo }}=7.49$; $\mathrm{F}(1,135)=.92, p=.34)$. In the Other condition, in which responses were presumably more aligned with true preferences, the Shampoo Type difference was significant $(\mathrm{F}(1$, $135)=15.01, p<.001)$; the average preference for the sustainable baby shampoo (versus the less sustainable baby shampoo) was 7.20, and the average preference for the sustainable car shampoo (versus the less sustainable car shampoo) was 6.13. Thus, when the potential for socially desirable responding is lessened through the use of the projective technique, the preference for the sustainable car shampoo (a

6This order effect may be due to the idea of babies priming concepts such as care-taking and/or taking a more long-term view about how a person will leave the planet for his or her children. This prime may increase participants' relative preference for sustainable brands across both product categories. We thank an anonymous reviewer for this suggestion. 
FIGURE 2

Study 2: The Influence of Point of View on Relative Preference for a Sustainable Versus Less Sustainable Baby Shampoo and Car Shampoo

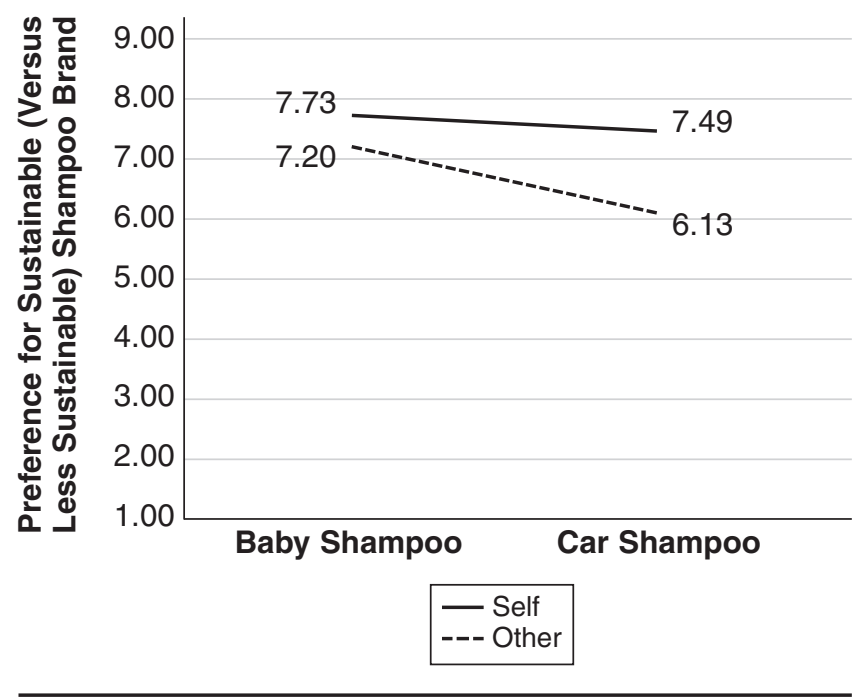

product category in which strength is valued more than gentleness) is attenuated.

\section{Discussion}

The results of Study 2 support $\mathrm{H}_{2}$ : Sustainability is more of an asset when gentleness-related attributes are valued more than strength-related attributes. By studying relative preferences within two similar product categories, we demonstrated the moderating role of type of benefit sought while minimizing the potential for confounds inherent in crosscategory comparisons.

What implications do these findings have for marketers? In product categories in which sustainability is an asset, marketers can benefit from promoting the ethical features of their product. In product categories in which strength is valued, however, marketers face a potential problem in that the benefits of sustainability can be attenuated; even worse, sustainability could be a liability. Study 3 explores whether sustainability can be a liability to such an extent that participants in the Other condition express greater relative preference for a less (versus more) sustainable brand when strength is especially valued.

\section{Study 3: Product Preference When Strength-Related Attributes Are Especially Valued}

The objective of Study 3 was to provide additional evidence for $\mathrm{H}_{2}$ in a product category in which strength-related attributes are especially valued. To this end, we selected laundry detergent as the product.

\section{Pretest}

We asked 43 undergraduate students to "rate how important each of the following dimensions/characteristics are to you when you buy laundry detergent" on the same items used in the pretest in Study 2. As we expected, the items loading on the Strong factor (e.g., "powerful," "tough") $(\mathrm{M}=5.53)$ were rated as significantly more important than the items loading on the Gentle factor (e.g., "safe," "mild") $(\mathrm{M}=$ $4.25 ; \mathrm{F}(1,42)=34.09, p<.0001)$.

\section{Stimuli and Procedure}

Seventy-six undergraduate students participated in the study in exchange for extra course credit. To both the right and the left of the computer monitors where participants were seated during the study lay a folded grey T-shirt. Behind each T-shirt was a bottle of laundry detergent in which the respective T-shirt had purportedly been washed. In reality, both T-shirts were washed in a third nonscented detergent, so the T-shirt stimuli did not actually differ. The detergent placed behind one T-shirt was Seventh Generation, a detergent promoted as a sustainable alternative ("Tough on dirt but gentle on ... the environment"), and the detergent behind the other T-shirt was Purex, a detergent that makes no claims about sustainability. ${ }^{7}$ Consistent with Study 2, we employed a Point of View manipulation; participants responded either from their own perspective or from that of the "average person." Thus, the study had a 2 (Point of View: Self versus Other) $\times 2$ (Order of Placement of the Detergent Bottles: Left versus Right) design. Order had no main or interactive effects, and we do not discuss it further.

Participants were instructed to inspect both bottles of detergent, including the labels. After inspecting the bottles, participants rated their relative familiarity with the brands on a seven-point scale, with 1 anchored by one detergent and 7 anchored by the other detergent, as well as their perceptions of the relative sustainability of the two detergents. Finally, using a seven-point scale with the ends anchored by the detergent brand names, participants identified which detergent, if either, they would prefer to use "regardless of cost."

\section{Results and Discussion}

As in Study 2, we converted all ratings such that the sustainable brand always anchored the high end of the scale (corresponding to a rating of seven). We removed 8 participants from the Other condition from the sample because they failed the Point of View manipulation check. ${ }^{8}$ This left a usable sample of 68 participants. As a manipulation check, we tested whether participants correctly identified which detergent was more sustainable, and the results show that they did $(\mathrm{M}=6.00$, significantly different from the scale midpoint of four; $\mathrm{F}(1,67)=113.90, p<.0001)$. Next, we regressed relative detergent preference on Point of View. There was no overall preference for either detergent $(\mathrm{M}=$ 3.60 , not significantly different from the scale midpoint of

\footnotetext{
${ }^{7}$ Consumer Reports (2008) rated Seventh Generation's overall performance as 59 out of 100 points. Purex received a somewhat lower score of 47 . Note that Seventh Generation's slightly better performance score arguably provides a conservative test of the hypothesis.

${ }^{8}$ The results when we retained participants who failed the manipulation check were similar to those when we dropped these participants. Specifically, a significant Point of View effect $(\mathrm{F}(1$, $74)=13.77, p<.001)$ on preference also emerged in the full data set.
} 
four; $\mathrm{F}(1,67)=1.85, p=.18)$. As we expected, however, there was a significant effect of Point of View on preference $(\mathrm{F}(1$, $66)=10.27, p<.01)$. Follow-up analyses using the spotlight method indicated that while participants in the Self condition did not significantly prefer either detergent $(M=4.36$, not significantly different from the scale midpoint; $\mathrm{F}(1,66)=$ $.99, p=.32)$, participants in the Other condition expressed a strong preference for the less sustainable detergent $(\mathrm{M}=$ 2.59 , significantly below the scale midpoint, in support of $\left.\mathrm{H}_{2} ; \mathrm{F}(1,66)=11.39, p<.01\right)$. Thus, Study 3 demonstrates that when strength is more valued than gentleness, the benefit of sustainability can be attenuated to such a degree that there is greater preference for the less sustainable brand.

Note that though there are obvious advantages to using real brands of detergent, we were concerned that the relative familiarity of Seventh Generation versus Purex induced the results. However, there was not a significant relationship between relative preference and rated differences in familiarity with the detergents $(\mathrm{F}(1,66)=2.16, p=.15)$ and no interactive effect of familiarity and Point of View $(F(1,64)=$ $.66, \mathrm{p}=.42$ ), so familiarity cannot underlie the preference results. Nonetheless, to more convincingly rule out the possibility that familiarity drives the results, in Study 4, we return to the previous use of fictitious brands to replicate the sustainability liability in an additional product category. We also obtain process evidence to demonstrate that the liability is driven by differential perceptions of product strength for products varying in sustainability. Study 4 also explores how managers can attenuate the sustainability liability.

\section{Study 4: Overcoming the Sustainability Liability with Explicit Information About Product Strength}

In this study, we turn our attention to how managers can attenuate the sustainability liability. Recall that in $\mathrm{H}_{3}$, we predicted that sustainability is less of a liability when sustainable products are explicitly portrayed as being strong than when no such information is provided. In Study 4, we explore participants' preferences for a sustainable (versus less sustainable) brand of car tire when explicit strength information is either present or absent.

\section{Pretest}

We performed a pretest to confirm the expectation that people value strength more than gentleness when purchasing automobile tires. A total of 75 pretest participants responded to the questions, "How important is it to you that the car tires you buy are strong" and "How important is it to you that the car tires you buy are gentle," both on nine-point scales. As we expected, Strong $(\mathrm{M}=8.48)$ was rated as significantly more important than Gentle $(\mathrm{M}=2.93 ; \mathrm{F}(1,74)=$ 405.98, $p<.0001)$.

\section{Stimuli and Procedure}

A total of 311 undergraduate students participated in this study in exchange for extra course credit. Given the results of the prior studies, this study includes only a projective condition (i.e., Other). To ensure that participants understood the Point of View manipulation, we presented them with a similar manipulation check item to that used in the prior studies. Participants were told that they would be participating in a study on car tires and that car tires differ on two major attributes:

-The materials from which they are made:

All car tires are made from oil and rubber. Traditionally, car tires have been made using methods and materials that are not very sustainable. There are car tires on the market today, termed "eco-tires," that are made using sustainable methods and materials, such as using recycled rubber (recycled from a number of sources) and alternative plant-derived ingredients. ${ }^{9}$

-The guarantee that the manufacturer of the car tires makes to consumers:

Guaranteed STRONG or Guaranteed AVAILABLE IN YOUR AREA.

Participants were shown the four possible combinations of these two attributes: 2 (Sustainability: sustainable versus less sustainable) $\times 2$ (Guarantee Type: strength versus "available in your area" [the control condition]). Participants were then asked to rate a hypothetical brand of car tires (called "Brand A"), the description of which we manipulated between subjects to be a sustainable tire brand with a strength guarantee, a sustainable tire brand with an availability guarantee, a less sustainable tire brand with a strength guarantee, or a less sustainable tire brand with an availability guarantee (for details, see Figure 3). Partici-

\footnotetext{
${ }^{9}$ Note that this type of "eco-tire" is available in the U.S. market today.

FIGURE 3

Study 4: Descriptions of Car Tire Manipulated Between Subjects
}

\begin{tabular}{|c|c|}
\hline $\begin{array}{l}\text { Sustainable Brand with } \\
\text { Strength Guarantee: } \\
\text {-CAR ECO-TIRE: Made } \\
\text { using sustainable methods } \\
\text { and materials, such as } \\
\text { recycled rubber and } \\
\text { alternative plant-derived } \\
\text { ingredients. } \\
\text {-Guaranteed STRONG }\end{array}$ & $\begin{array}{l}\text { Sustainable Brand with } \\
\text { Availability Guarantee: } \\
\text {-CAR ECO-TIRE: Made } \\
\text { using sustainable methods } \\
\text { and materials, such as } \\
\text { recycled rubber and } \\
\text { alternative plant-derived } \\
\text { ingredients. } \\
\text {-Guaranteed AVAILABLE IN } \\
\text { YOUR AREA. }\end{array}$ \\
\hline $\begin{array}{l}\text { Less Sustainable Brand } \\
\text { with Strength Guarantee: } \\
\text {-CAR TIRE: Made using } \\
\text { traditional methods and } \\
\text { materials, including non- } \\
\text { recycled rubber and other } \\
\text { ingredients traditionally } \\
\text { used by car tire } \\
\text { manufacturers. } \\
\text {-Guaranteed STRONG }\end{array}$ & $\begin{array}{l}\text { Less Sustainable Brand } \\
\text { with Availability } \\
\text { Guarantee: } \\
\text { •CAR TIRE: Made using } \\
\text { traditional methods and } \\
\text { materials, including non- } \\
\text { recycled rubber and other } \\
\text { ingredients traditionally } \\
\text { used by car tire } \\
\text { manufacturers. } \\
\text {-Guaranteed AVAILABLE IN } \\
\text { YOUR AREA. }\end{array}$ \\
\hline
\end{tabular}


pants responded to the question, "How durable would the average American think Brand A car tires are?" on a scale ranging from 1 ("not at all durable") to 9 ("very durable") and to the question, "How long-lasting would the average American think Brand A car tires are?" on a scale ranging from 1 ("not at all long-lasting") to 9 ("very long-lasting").

Participants then read the following instructions: "For the rest of today's questions, please tell us what you personally think. This can be the same or different from what you thought the average American would think." The purpose of changing participants' Point of View at this point in the study was to employ a slightly different dependent variable. Rather than asking participants to indicate relative preference between a more sustainable and a less sustainable brand, as we had done in prior studies, we asked them to respond to the question, "Do you personally (not the average American) think Brand A car tires are a best-selling brand in the U.S. today?" on a scale ranging from 1 ("no, definitely not") to 9 ("yes, definitely"). Note that this technique is still a projective technique in that participants are indicating which type of tires they believe others would purchase, but this measure more directly assesses participants' thoughts about others' choices than relative preference. Finally, using the same scale, we asked participants, "Do you personally think that the guarantee offered by Brand A car tires is believable?"

\section{Results}

We removed 30 participants from the sample because they failed the Point of View manipulation check. ${ }^{10}$ This left a usable sample of 281 participants. To test $\mathrm{H}_{3}$, we subjected the best-seller dependent variable to a 2 (Sustainability: sustainable versus less sustainable) $\times 2$ (Guarantee Type: strength versus availability) analysis of variance. Both main effects were significant; participants reported that less sustainable tires $(\mathrm{M}=6.21)$ would sell better than the sustainable tires $(\mathrm{M}=3.92 ; \mathrm{F}(1,277)=58.76, p<.0001)$, and they reported that tires associated with the strength guarantee $(\mathrm{M}=5.55)$ would sell better than tires associated with the availability guarantee $(\mathrm{M}=4.58 ; \mathrm{F}(1,277)=10.70, p<$ $.01)$. Most important, the Sustainability $\times$ Guarantee Type interaction was significant $(\mathrm{F}(1,277)=3.50, p=.06)$. Follow-up spotlight analyses revealed that type of guarantee did not have a significant effect in the less sustainable tire condition $(\mathrm{F}(1,277)=.95, p=.33)$. However, participants who saw a sustainable tire with a strength guarantee indicated that the tire was significantly more likely to be a best seller than participants who saw a sustainable tire with an availability guarantee $(\mathrm{F}(1,277)=3.69, p<.001)$. The pattern of the interaction demonstrates that the negative impact of sustainability can be attenuated if a sustainable product is accompanied by explicit information about product strength (for details, see Figure 4, Panel A).

${ }^{10}$ The results when we retained participants who failed the manipulation check were similar to those when we dropped these participants. Specifically, a significant Sustainability $\times$ Guarantee Type interaction predicting participants' perceptions of whether the car tire was a best seller also emerged in the full data set $(\mathrm{F}(1$, $307)=3.50, p=.06)$.
FIGURE 4 Study 4: Beliefs About Car Tire Brand by
Sustainability and Guarantee Type

A: Participants' Beliefs About Whether Car Tire Brand Is a Best Seller in the United States Today by Sustainability and Guarantee Type
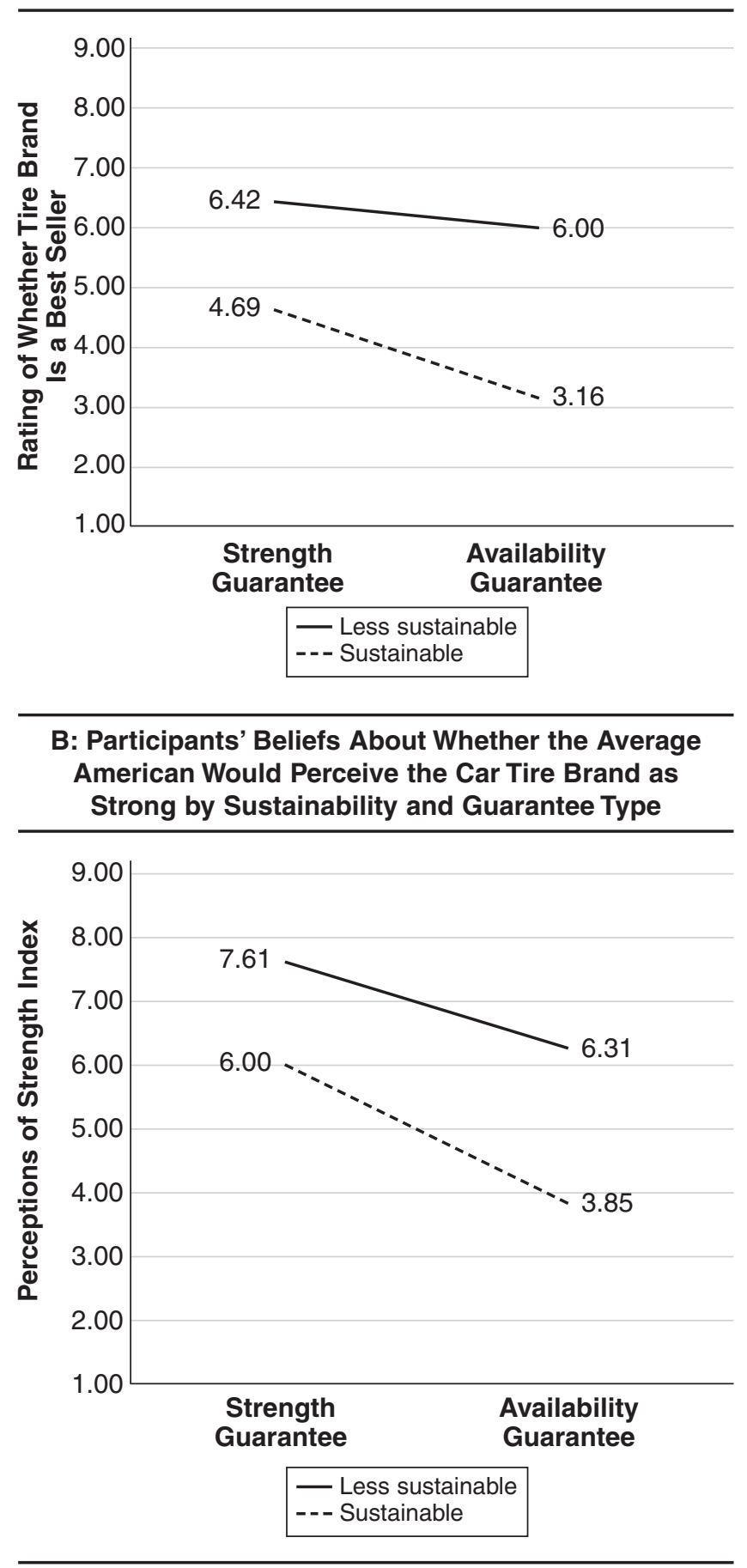

To demonstrate that the interactive effect of Sustainability and Guarantee Type on perceptions that the tire is a best seller is not driven by differences in the believability of the guarantee, we next ran a 2 (Sustainability) $\times 2$ (Guarantee Type) analysis of variance using believability as the dependent measure. There was no interactive effect of Sustainability and Guarantee Type on believability $(\mathrm{F}(1,277)=$ 
$.18, p=.67)$. Thus, believability does not drive the focal interaction. However, according to our theory, the differences in the best-seller dependent variable should be driven by perceptions of the durability of the tire and perceptions of how long the tire would last, that is, the strength of the tire.

The ratings of durability and long-lastingness were highly correlated $(\mathrm{r}=.83)$, and thus we first averaged them to form a "perceptions of strength" index. As we expected, both Guarantee Type and Sustainability significantly influenced perceptions of strength, with respondents indicating that the average American would think that the less sustainable tire was stronger $(\mathrm{M}=6.96)$ than the sustainable tire $(\mathrm{M}=4.92 ; \mathrm{F}(1,277)=123.17, p<.001)$ and that the tire with the strength guarantee $(M=6.08)$ was stronger than the tire with the availability guarantee $(\mathrm{M}=5.08 ; \mathrm{F}(1,277)=$ $88.26, p<.001)$. Most important, the Sustainability $\times$ Guarantee Type interaction was also significant $(\mathrm{F}(1,277)=$ $5.45, p<.05)$ : The effect of Guarantee Type was greater in the sustainable condition $(\mathrm{F}(1,277)=70.52, p<.0001)$ than in the less sustainable condition $(\mathrm{F}(1,277)=24.33, p<$ $.0001)$. Because participants believe that a sustainable product is not as strong, in general, as a less sustainable product, the addition of an explicit guarantee of strength has an even more powerful effect on perceptions of strength for sustainable products (for details, see Figure 4, Panel B).

Finally, we tested whether perceptions of strength mediated the interactive effect of Sustainability and Guarantee Type on the best-seller dependent variable (Baron and Kenny 1986). Indeed, when we include the perceptions of strength index in the model, the interaction term is no longer a significant predictor of participants' beliefs about whether the car tire is a best seller $(\mathrm{F}(1,276)=.83, p=.36$; Sobel $\mathrm{Z}=2.22, p<.05)$.

\section{Discussion}

The results of Study 4 support $\mathrm{H}_{3}$; the sustainability liability observed when no explicit information is provided about product strength is attenuated when consumers are reassured that the sustainable product is strong. Note that by manipulating information about product strength, we are examining the psychological mechanism we propose by manipulating this process (i.e., manipulating perceptions of product strength) to moderate the relationship between sustainability and product preference (for a discussion of this technique, see Spencer, Zanna, and Fong 2005). Thus, Study 4 provides both indirect process evidence and direct process evidence (through mediation analysis) that the sustainability liability is indeed due to consumers' perceptions that sustainable products are not as strong as less sustainable products. Study 4 is also substantively important in that it suggests a way for managers of sustainable brands to combat the sustainability liability through explicit information about product strength. In Study 5, we focus further on the substantive implications of this research by demonstrating that the sustainability liability affects consumers' choices outside the lab.

\section{Study 5: Observational Field Study}

Because we conducted Studies 1-4 in controlled laboratory environments using projective techniques, managers of sustainable products could question whether the sustainability liability affects consumers' decision making in a real consumption context. Therefore, in Study 5, we elicit actual consumer choices in a context with potentially significant consequences: the choice of a liquid hand sanitizer designed to kill bacteria and viruses. With the threat of contracting the H1N1 virus (i.e., swine flu) being highly salient at the time we conducted the study, strength, specifically the ability to kill the H1N1 virus, is an important attribute in this product category. ${ }^{11}$ Thus, we expected people to prefer to use a less sustainable hand sanitizer over a sustainable hand sanitizer.

\section{Stimuli and Procedure}

A small table was placed near one of the entrances to the cafeteria of the business school at a large state university. Two (8-ounce) hand sanitizer bottles were displayed on the table, both variants of a relatively unknown private-label brand (Target's "up \& up" brand). The sanitizing liquid in one of the bottles was green, and that in the other bottle was clear. A sign behind the bottle with the green sanitizer read, "Up \& Up Green (Eco Friendly)," and a sign behind the bottle with the clear sanitizer read, "Up \& Up White (Regular)." Thus, the bottle with the green sanitizing liquid was presented as a sustainable alternative (in reality, neither version actually makes claims about sustainability). Finally, to increase the realism of why a hand sanitizer station was being set up, a $24 \times 36$-inch poster, which read, "Swine Flu Alert. Use Hand Sanitizers as Often as Possible," was placed on the table.

A confederate observed and recorded use of the two hand sanitizers. For approximately half the duration of the study, the confederate sat close to the hand sanitizer station with an open laptop. The confederate was close enough to the table for those who used a hand sanitizer to realize that their choices were being observed and recorded. For the remainder of the time, the confederate was positioned such that people using a hand sanitizer were not aware their choices were being recorded (the confederate sat behind a pillar at some distance from the table and observed the hand sanitizer choices surreptitiously). We also manipulated the position of the hand sanitizers so that the green hand sanitizer was on the right-hand side of the table for half the duration of the study and on the left-hand side of the table for the other half. The position of the hand sanitizer had no main or interactive effects on choice of hand sanitizer, and we do not discuss it further. A total of 51 participants were observed using one of the hand sanitizers during an 11-hour period (approximately 5 hours with the confederate in an

${ }^{11}$ The study was conducted during October 2009 when fear about swine flu was high. Just before this study was conducted, the dean's office (at the school in which the study was conducted) had sent out an e-mail alert informing students and employees about the risk of swine flu and recommending the use of hand sanitizers to mitigate the chances of contracting the $\mathrm{H} 1 \mathrm{~N} 1$ virus. 
easily observable position and 6 hours with the confederate hidden).

\section{Results and Discussion}

Though not precluded from doing so, none of the participants chose to use both hand sanitizers; each participant selected either the sustainable (green) hand sanitizer or the less sustainable (white) hand sanitizer. A logistic regression showed a significant relationship between type of hand sanitizer chosen and confederate proximity $\left(\chi^{2}(1,50)=9.58, p<\right.$ $.01)$. Figure 5 presents these results. Follow-up spotlight analyses revealed that when the confederate was nearby, a significant proportion of participants chose the green (versus white) hand sanitizer $\left(72 \%\right.$ versus $28 \% ; \chi^{2}(1,50)=$ $4.50, p<.05)$. However, when the confederate was not visible, a significant proportion of participants chose the white (versus green) hand sanitizer $\left(73 \%\right.$ versus $27 \% ; \chi^{2}(1,50)=$ $5.19, p<.01)$.

Thus, in a nonlaboratory decision with actual choices, Study 5 shows that sustainability is a liability for product choice when strength is especially valued. It also shows that people are not as likely to reveal this preference when they know that their choices are being observed, providing additional evidence for the contention that projective techniques (which allow respondents to reveal their choices without feeling personally observed) are useful in revealing actual preference in the domain of ethical decision making.

\section{General Discussion}

Growing concerns about a variety of social and environmental issues may be ushering in an era in which concern about sustainability crosses the chasm (Moore 1991) from a fringe movement espoused by a niche of consumers to a

\section{FIGURE 5 \\ Study 5: Participants' Choice of Hand Sanitizer (Sustainable Versus Less Sustainable) by Confederate Position (Nearby Versus Not Visible)}

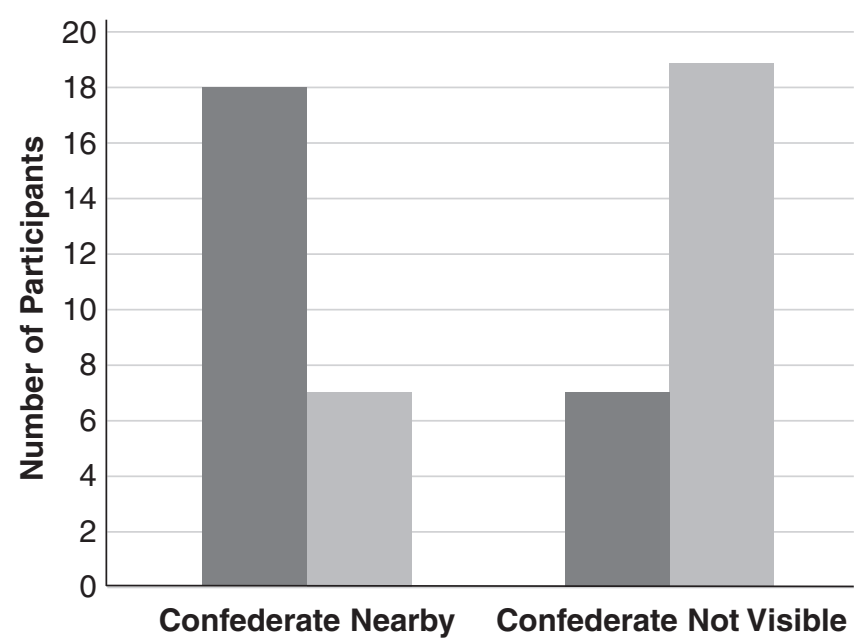

Chose green (sustainable) hand sanitizer Chose white (less sustainable) hand sanitizer broader trend that influences the consumption patterns of the mainstream market. Issues such as global warming and resource usage present real threats that society must confront, and they also present significant opportunities for marketers. Companies that successfully respond to these threats by developing and promoting products that appeal to consumers' ethical values can benefit society while fulfilling company objectives of achieving long-term profitable growth.

With these evolving opportunities, however, come real challenges. The goal of this research was to demonstrate that product sustainability, though appealing as a virtue on its own, can be either a liability or an asset with respect to consumer preferences and choice. The effect of sustainability on preference is not uniformly positive (or negative), because the presence of sustainability affects consumers' judgments about other product attributes.

\section{Theoretical Contributions}

The findings advance the understanding of the effect of sustainability on consumer decisions in several ways. First, we document consumers' associations between superior ethicality and gentleness-related attributes and between lower ethicality and strength-related attributes (Study 1). To the best of our knowledge, this research is the first empirical demonstration of these associations.

Second, we show that whether sustainability is an asset depends on the type of benefit valued in the product category (Studies 2-5). In Studies 3-5, we demonstrate that sustainability is a liability (with respect to product preference) across three different product categories in which strength is valued: laundry detergent, automobile tires, and liquid hand sanitizer. The results from these studies suggest that when ethics are involved, consumer judgments are not explained by unidirectional processes identified in prior literature, such as halo effects (Asch 1946; Nisbett and Wilson 1977; Thorndike 1920) or the simple trading off of attribute performance assumed under market efficiency (Chernev and Carpenter 2001), because sustainability does not uniformly increase either negative or positive response to products.

This research also supports recent findings exploring the impact of CSR on product evaluations. The CSR literature initially focused on the positive impact of CSR initiatives on product and company evaluations (Brown and Dacin 1997). More recent research in this area has presented a more nuanced approach similar in spirit to our theorizing, in that it has focused on identifying specific circumstances under which CSR might or might not lead to uniformly positive product evaluations (Luo and Bhattacharya 2006; Sen and Bhattacharya 2001). Note that this prior research and the current findings do not suggest that companies should not strive to be ethical. However, taken together, these research streams suggest that the effect of ethicality on a host of important variables, including purchase intention, satisfaction, and product preference, is complex.

Finally, we show that consumers' negative expectations of sustainable products can be mitigated. Study 4 demonstrates that when ethical attributes are present, explicit 
information about product strength is particularly important. This information can be used to reassure consumers that sustainable products also perform well, even in categories in which strength is especially valued. Thus, the findings contribute to the literature on the interplay between lay beliefs and inference making (Broniarczyk and Alba 1994; Raghunathan, Naylor, and Hoyer 2006), demonstrating that consumers do not rely on lay theories when explicit information about missing attributes is provided.

\section{Practical Implications}

Given the relative success of some categories and brands of sustainable products, the industry trend toward more product sustainability appears to be well founded. However, this research provides some insight into the challenges that companies face as they introduce more sustainable product alternatives, as well as guidance on what they can do to address these challenges.

Market research to determine the potential demand for sustainable products may lead decision makers to believe that a large segment of consumers will purchase sustainable products only to find that, depending on the product category and promotion strategy, sales of these products fall far below expectations. Although traditional research methods may be appropriate for some product categories, companies may want to consider indirect ways of assessing the potential demand for sustainable products, such as the manipulation of the point of view from which respondents are asked to answer purchase intention questions. Given the difference in the results when social desirability concerns are mitigated compared with when they are not, this research suggests that projective techniques are important for both practitioners and academics who want to study consumer decision making when sustainability is involved.

This research also provides some guidance for companies that choose either to include ethical attributes in new products or to capitalize on sustainable products already in their portfolios. For product categories in which strengthrelated attributes are valued, companies promoting sustainable products may need to pay special attention to countering the association between sustainability and lower product strength. For example, as the findings from Study 4 indicate, companies might explicitly promote the strength of these products in addition to their sustainability. This can be accomplished by modifying the traditional marketingmix elements, including information provided in promotions, on packaging, and so forth. Brand names might also be used as explicit strength cues. Companies interested in producing sustainable products in categories in which strength is valued should consider cobranding with brands already associated with strength. The relatively recent introduction of Clorox's Green Works is an example of this type of branding strategy employed to introduce a new sustainable product line. Note that Clorox (2010) also gives explicit strength cues in describing the effectiveness of its products (e.g., "Green Works ${ }^{\circledR}$ natural laundry detergent still cleans with the power you expect from the people at Clorox").

In addition, given the finding that consumers judge sustainable products to have superior performance in terms of gentleness-related attributes (e.g., safety, healthfulness), marketers should consider pursuing brand and product line expansion strategies that benefit the most from association with these product attributes. Indeed, some brands already appear to take advantage of the sustainability-gentleness relationship. Burt's Bees, acquired in 2007 by Colgate for almost $\$ 1$ billion, specializes in natural personal care products, including children's products and products for pregnant women. The Burt's Bees (2010) product line emphasizes gentleness as well as ethics and sustainability (e.g., "Make bath time naturally healthy with these formulas that gently cleanse and soften baby's skin") and has proved to be successful.

\section{Limitations and Further Research}

We believe that our results will generalize to many other product categories in which strength or gentleness are valued, but the results will not necessarily apply in product categories in which neither of these two attributes is an important determinant of product choice. In addition, when we conceptualize "strength" and "gentleness," we refer to these attributes in a physical sense. We do not expect a similar inference about strong-tasting or strong-smelling food, for example, because the lay theory that we propose consumers hold is specific to an inverse relationship between ethicality and physical strength. In product categories in which product choice is determined by non-strength-related attributes, the degree to which ethicality increases preference depends on the specific relationship between ethicality and the attribute driving product choice. For example, sustainable brands may be viewed as more homegrown and simple than less sustainable brands. Less sustainable products may be considered more sophisticated and sexy than sustainable products. The interaction of ethicality with other types of benefits sought from the product is an important area for further research.

Further research can also address situations in which the sustainability liability will not be observed even in product categories for which strength is especially valued. Study 5 suggests that whether a product is consumed in public or in private will affect whether consumers are reluctant to choose a sustainable brand. In highly observable contexts, consumers may be more rather than less likely to choose sustainable brands because of social desirability concerns (i.e., either to avoid appearing as if they do not care about ethical issues or to publicly demonstrate their commitment to a particular ethical cause).

Finally, the results suggest that the associations between superior ethicality and gentleness and between lack of ethicality and strength will extend beyond a product context. For example, ethical service providers (e.g., attorneys) may be viewed as less able to provide effective service (e.g., less aggressive representation of their clients) than their less ethical counterparts. These associations may also extend to perceptions of corporations as a whole, such that ethical corporations may be viewed as less strong and less powerful overall than less ethical corporations. We leave these as possibilities for further research to address. 


\section{Conclusion}

Many of the environmental and social problems that people report caring about could be at least partially corrected if marketplace behavior reflected deeply held values. Sometimes people say that they hold values that, in reality, they do not, but we propose that other mechanisms may also underlie the discrepancy between reported values and actual consumption behavior. We show in this research that though sustainability can be a marketing asset in categories in which gentleness is especially valued, it can be a liability in categories in which strength is especially valued. Fortunately, as this research demonstrates, it is likely that companies can overcome the sustainability liability with an appropriate positioning and promotion strategy. This knowledge should improve the odds of success for companies interested in marketing sustainable products and should support many consumers' desires to better align their values and their consumption behavior.

\section{REFERENCES}

Alpert, Mark I. (1971), "Identification of Determinant Attributes: A Comparison of Methods," Journal of Marketing Research, 8 (May), 184-91.

Asch, Solomon Elliott (1946), "Forming Impressions of Personality," Journal of Abnormal and Social Psychology, 41 (July), 258-90.

Baron, Jonathan and Mark Spranca (1997), "Protected Values," Organizational Behavior and Human Decision Processes, 70 (April), 1-16.

Baron, Reuben M. and David A. Kenny (1986), "The ModeratorMediator Variable Distinction in Social Psychological Research: Conceptual, Strategic, and Statistical Considerations," Journal of Personality and Social Psychology, 51 (December), 1173-82.

BBMG (2007), "The BBMG Conscious Consumer Report," (accessed June 2, 2008), [available at http://www.bbmg.com].

Beaven, Colin (2009), "Finding Promise in Sustainability 2.0," BusinessWeek, (September 3), (accessed April 23, 2010), [available at http://www.businessweek.com/magazine/content/ 09_37/b4146068075848.htm].

Betts, Kate (2009), "The Journey from Plastic to Paper," Time, (May 1), (accessed April 23, 2010), [available at http://www. time.com/time/magazine/article/0,9171,1895336,00.html].

Blatt, Sidney J. (1975), "The Validity of Projective Techniques and Their Research and Clinical Contribution," Journal of Personality Assessment, 39 (August), 327-43.

Broniarczyk, Susan M. and Joseph W. Alba (1994), "The Role of Consumers' Intuitions in Inference Making," Journal of Consumer Research, 21 (December), 393-407.

Brown, Tom J. and Peter A. Dacin (1997), "The Company and the Product: Corporate Associations and Consumer Product Responses," Journal of Marketing, 61 (January), 68-84.

Burt's Bees (2010), "Earth Friendly Natural Personal Care Products for the Greater Good," (accessed February 23, 2010), [available at http://www.burtsbees.com].

Chernev, Alexander and Gregory S. Carpenter (2001), “The Role of Market Efficiency Institutions in Consumer Choice: A Case of Compensatory Inferences," Journal of Marketing Research, 38 (August), 349-61.

Clorox (2010), "Green Works Natural Laundry Detergent," (accessed February 23, 2010), [available at http://www. greenworkscleaners.com/laundry/detail.php?id=nhdl].

Consumer Reports (2007), "It's Not Easy Buying Green," (accessed June 2, 2008), [available at http://www.consumerreports.org/ cro/home-garden/news/2007/09/buying-environmentalfriendly-products/overview/0709_green_ov_1.htm].

- (2008), "Laundry Detergent and Interior Paint Ratings," (accessed June 2, 2008), [available at http://www.consumerreports. org].

Dick, Alan, Dipankar Chakravarti, and Gabriel Biehal (1990), "Memory-Based Inferences During Choice," Journal of Consumer Research, 17 (June), 82-93.
Ehrich, Kristine R. and Julie R. Irwin (2005), "Willful Ignorance in the Request for Product Attribute Information," Journal of Marketing Research, 42 (August), 266-77.

Epley, Nick, Boaz Keysar, Leaf Van Boven, and Thomas Gilovich (2004), "Perspective Taking as Egocentric Adjustment," Journal of Personality and Social Psychology, 87 (September), 327-39.

Finucane, Melissa L., Ali Alhakami, Paul Slovic, and Stephen M. Johnson (2000), "The Affect Heuristic in Judgments of Risks and Benefits," Journal of Behavioral Decision Making, 13 (January-March), 1-17.

Fisher, Robert J. (1993), "Social Desirability Bias and the Validity of Indirect Questioning," Journal of Consumer Research, 20 (September), 303-315.

Fiske, Susan T. and Mark A. Pavelchak (1986), "Category-Based Versus Piecemeal-Based Affective Responses: Developments in Schema Triggered Affect," in Handbook of Motivation and Cognition: Foundations of Social Behavior, R.M. Sorrentino and E.T. Higgins, eds. New York: Guilford Press, 167-203.

Gildea, Robert L. (2001), "Consumer Survey Confirms Corporate Social Action Affects Buying Decisions," Public Relations Quarterly, 39 (Winter), 20-21.

Gini, Al (2006), Why It's Hard to Be Good. New York: Routledge.

Greenwald, Anthony G., Debbie E. McGhee, and Jordan L.K. Schwarz (1998), "Measuring Individual Differences in Implicit Cognition: The Implicit Association Test," Journal of Personality and Social Psychology, 74 (June), 1464-80.

, Brian A. Nosek, and Mahzarin R. Banaji (2003), "Understanding and Using the Implicit Association Test: I. An Improved Scoring Algorithm," Journal of Personality and Social Psychology, 85 (September), 197-216.

Gunther, Marc (2006), “The Green Machine,” Fortune, (July 31), (accessed April 23, 2010), [available at http://money.cnn.com/ magazines/fortune/fortune_archive/2006/08/07/8382593/index. htm].

Haire, Mason (1950), "Projective Techniques in Marketing Research," Journal of Marketing, 14 (April), 649-56.

Hussey, Michael and Nicola Duncombe (1999), "Projecting the Right Image: Using Projective Techniques to Measure Brand Image," Qualitative Market Research: An International Journal, 2 (1), 22-30.

Irwin, Julie R. and Jonathan Baron (2001), "Response Mode Effects and Moral Values," Organizational Behavior and Human Decision Processes, 84 (March), 177-97.

and Gary H. McClelland (2001), "Misleading Heuristics and Moderated Multiple Regression Models," Journal of Marketing Research, 38 (February), 100-109.

and Rebecca Walker Naylor (2009), "Ethical Decisions and Response Mode Compatibility: Weighting of Ethical Attributes in Consideration Sets Formed by Excluding Versus Including Product Alternatives," Journal of Marketing Research, 46 (April), 234-46. 
Johnson, Keith (2009), "Tagged: Wal-Mart's Big Push for EcoLabels," The Wall Street Journal, (July 15), (accessed April 23, 2010), [available at http://blogs.wsj.com/environmentalcapital/ 2009/07/15/tagged-wal-marts-big-push-for-eco-labels/tab/ article/]

Kanov, Jason M., Sally Maitlis, Monica C. Worline, Jane E. Dutton, Peter J. Frost, and Jacoba M. Lilius (2004), "Compassion in Organizational Life," American Behavioral Scientist (special issue on Contributions to Positive Organizational Scholarship), 47 (6), 808-827.

Kelly, Harold H. and John W. Thibaut (1969), "Group Problem Solving," in Handbook of Social Psychology, Vol. 4, 2d ed., Gardner Lindsey and Elliot Aronson, eds. Reading, MA: Addison-Wesley, 134-73.

Kruger, Justin and Thomas Gilovich (2004), “Actions, Intentions, and Self-Assessment: The Road to Self-Enhancement Is Paved with Good Intentions," Personality and Social Psychology Bulletin, 30 (March), 328-39.

Luo, Xueming and C.B. Bhattacharya (2006), "Corporate Social Responsibility, Customer Satisfaction, and Market Value," Journal of Marketing, 70 (October), 1-18.

Luthans, Fred and Carolyn M. Youssef (2007), "Emerging Positive Organizational Behavior," Journal of Management, 33 (3), 321-49.

Moore, Geoffrey A. (1991), Crossing the Chasm: Marketing and Selling Technology Products to Fainstream Customers. New York: HarperBusiness.

Morris, Michael W., Tanya Menon, and Daniel R. Ames (2001), "Culturally Conferred Conception of Agency: A Key to Social Perception of Persons, Groups, and Other Actors," Personality and Social Psychology Review, 5 (April), 169-82.

Nisbett, Richard E. and Timothy D. Wilson (1977), "The Halo Effect: Evidence for the Unconscious Alteration of Judgments," Journal of Personality and Social Psychology, 35 (April), 450-56.

O'Donohoe, Stephanie and Darach Turley (2006), "Compassion at the Counter: Service Providers and Bereaved Customers," Human Relations, 59 (10), 1429-88.

Paulhus, Delroy L. (1984), "Two-Component Models of Socially Desirable Responding," Journal of Personality and Social Psychology, 46 (March), 598-609.
Porges, Susan (2007), Ethical Consumers and Corporate Responsibility: The Market and Trends for Ethical Products in Food and Beverage, Personal Care and Household Items. New York: Packaged Facts.

Raghunathan, Rajagopal, Rebecca Walker Naylor, and Wayne D. Hoyer (2006), "The Unhealthy = Tasty Intuition and Its Effects on Taste Inferences, Enjoyment, and Choice of Food Products," Journal of Marketing, 70 (October), 170-84.

Sen, Sankar and C.B. Bhattacharya (2001), "Does Doing Good Always Lead to Doing Better? Consumer Reactions to Corporate Social Responsibility," Journal of Marketing Research, 38 (May), 225-43.

Sisodia, Raj, Jag Sheth, and David B. Wolfe (2007), Firms of Endearment. Upper Saddle River, NJ: Wharton School Publishing.

Spencer, Steven J., Mark P. Zanna, and Geoffrey T. Fong (2005), "Establishing a Causal Chain: Why Experiments Are Often More Effective Than Mediational Analyses in Examining Psychological Processes," Journal of Personality and Social Psychology, 89 (January), 845-51.

Story, Louise (2008), "Can Burt's Bees Turn Clorox Green?" The New York Times, (January 6), (accessed April 23, 2010), [available at http://www.nytimes.com/2008/01/06/business/06bees. html].

Sujan, Mita and Christine Dekleva (1987), "Product Categorization and Inference Making: Some Implications for Comparative Advertising," Journal of Consumer Research, 14 (December), 372-78.

Thorndike, Edward Lee (1920), "A Constant Error on Psychological Rating," Journal of Applied Psychology, 4 (March), 25-29.

Trudel, Remi and June Cotte (2008), "Does Being Ethical Pay?" (accessed October 5, 2008), [available at http://sloanreview. mit.edu/business-insight/articles/2008/2/].

United Nations Environment Programme (2005), "Talk the Walk: Advancing Sustainable Lifestyles Through Marketing and Communications," UN Global Compact and Utopies, (accessed April 23, 2010), [available at http://www.unep.fr/shared/ publications/pdf/DTIx0763xPA-TalkWalk.pdf].

Whole Foods Market (2010), "Sustainability and Our Future," (accessed February 23, 2010), [available at http://www. wholefoodsmarket.com/values/sustainability.php]. 